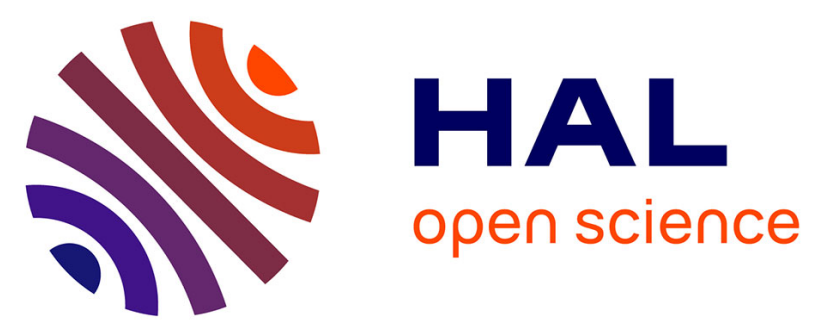

\title{
Structural features, anti-coagulant and anti-adhesive potentials of blue crab (Portunus segnis) chitosan derivatives: Study of the effects of acetylation degree and molecular weight
}

Marwa Hamdi, Rim Nasri, Ikram Ben Amor, S.M. Li, Jalel Gargouri, Moncef Nasri

\section{To cite this version:}

Marwa Hamdi, Rim Nasri, Ikram Ben Amor, S.M. Li, Jalel Gargouri, et al.. Structural features, anticoagulant and anti-adhesive potentials of blue crab (Portunus segnis) chitosan derivatives: Study of the effects of acetylation degree and molecular weight. International Journal of Biological Macromolecules, 2020, 160, pp.593 - 601. 10.1016/j.ijbiomac.2020.05.246 . hal-03093141

\section{HAL Id: hal-03093141 \\ https://hal.science/hal-03093141}

Submitted on 22 Feb 2021

HAL is a multi-disciplinary open access archive for the deposit and dissemination of scientific research documents, whether they are published or not. The documents may come from teaching and research institutions in France or abroad, or from public or private research centers.
L'archive ouverte pluridisciplinaire HAL, est destinée au dépôt et à la diffusion de documents scientifiques de niveau recherche, publiés ou non, émanant des établissements d'enseignement et de recherche français ou étrangers, des laboratoires publics ou privés. 


\section{Structural features, anti-coagulant and anti-adhesive potentials of blue crab (Portunus segnis) chitosan derivatives: Study of the effects of acetylation degree and molecular weight}

Rim Nasri, Ikram Amor, Suming Li, Jalel Gargouri, Moncef Nasri, Murat Kaya, Marguerite Rinaudo, Marwa Hamdi

\section{To cite this version:}

Rim Nasri, Ikram Amor, Suming Li, Jalel Gargouri, Moncef Nasri, et al.. Structural features, anticoagulant and anti-adhesive potentials of blue crab (Portunus segnis) chitosan derivatives: Study of the effects of acetylation degree and molecular weight. International Journal of Biological Macromolecules, Elsevier, 2020, 160, pp.593 - 601. 10.1016/j.ijbiomac.2020.05.246 . hal-03093141

\section{HAL Id: hal-03093141 \\ https://hal.archives-ouvertes.fr/hal-03093141}

Submitted on 22 Feb 2021

HAL is a multi-disciplinary open access archive for the deposit and dissemination of scientific research documents, whether they are published or not. The documents may come from teaching and research institutions in France or abroad, or from public or private research centers.
L'archive ouverte pluridisciplinaire HAL, est destinée au dépôt et à la diffusion de documents scientifiques de niveau recherche, publiés ou non, émanant des établissements d'enseignement et de recherche français ou étrangers, des laboratoires publics ou privés. 
International Journal of Biological Macromolecules

\section{Structural features, anti-coagulant and anti-adhesive potentials of blue crab (Portunus segnis) chitosan derivatives: Study of the effects of acetylation degree and molecular weight \\ --Manuscript Draft--}

\begin{tabular}{|c|c|}
\hline Manuscript Number: & IJBIOMAC_2020_719R1 \\
\hline Keywords: & anticoagulant.; Blue crab chitosan derivatives; Antiadhesive \\
\hline Corresponding Author: & $\begin{array}{l}\text { Marwa Hamdi } \\
\text { Ecole Nationale d'Ingenieurs de Sfax } \\
\text { Sfax, TUNISIA }\end{array}$ \\
\hline First Author: & Marwa Hamdi \\
\hline \multirow[t]{4}{*}{ Order of Authors: } & Marwa Hamdi \\
\hline & Rim Nasri \\
\hline & Jalel Gargouri \\
\hline & Moncef Nasri \\
\hline Abstract: & $\begin{array}{l}\text { The present study was undertaken to establish a distinct relationship between blue } \\
\text { crab chitosan (Cs) acetylation degree (AD) and molecular weight (Mw) and its } \\
\text { structural features, thermal properties and bioactivity. Therefore, chitosans with } \\
\text { different AD were prepared and Cellulase was used to produce Cs derivatives with } \\
\text { decreasing Mw. Results clearly display a decrease of the ordered structure of Cs, with } \\
\text { the increase of AD and the decrease of Mw. Thermal stability/degradation screening } \\
\text { disclose a greater thermal resistance for Cs with lower AD and higher Mw. The anti- } \\
\text { adhesive potential of Cs was, additionally, studied, as function of AD and Mw. The } \\
\text { effectiveness of Cs in preventing biofilm adhesion was strongly influenced by its AD } \\
\text { and Mw, with the lowest inhibition values for higher AD and lower Mw. Interestingly, the } \\
\text { effectiveness of Cs in disrupting pre-formed biofilms increased with decreasing Mw. } \\
\text { Moreover, Cs derivatives were found to be advantageously efficient in prolonging } \\
\text { human blood clotting times, based on data of activated partial thromboplastin time, } \\
\text { Quick time and thrombin time assays, typically for the intrinsic coagulation pathway. } \\
\text { Accordingly, depending on the predicted application of Cs, either in food, biomedical } \\
\text { and pharmaceutical industries, AD and Mw are critical traits to be inevitably reflected } \\
\text { on. }\end{array}$ \\
\hline \multirow[t]{3}{*}{ Suggested Reviewers: } & $\begin{array}{l}\text { Murat Kaya } \\
\text { muratkaya3806@yahoo.com }\end{array}$ \\
\hline & $\begin{array}{l}\text { Marguerite Rinaudo } \\
\text { marguerite.rinaudo38@gmail.com }\end{array}$ \\
\hline & $\begin{array}{l}\text { Koro de la Caba } \\
\text { koro.delacaba@ehu.eus }\end{array}$ \\
\hline \multicolumn{2}{|l|}{ Opposed Reviewers: } \\
\hline Response to Reviewers: & \\
\hline
\end{tabular}




\section{Highlights :}

- Chitosan derivatives with diverse acetylation degree (AD) and molecular weight (Mw);

- Greater thermal resistance for chitosan derivatives with lower $\mathrm{AD}$ and higher Mw;

- Lowest biofilm adhesion inhibition for higher $\mathrm{AD}$ and lower Mw chitosan derivatives;

- Disrupting pre-formed biofilms increase with decreasing chitosan derivatives Mw;

- Derivatives efficiency in prolonging clotting, typically for the intrinsic pathway. 


\begin{abstract}
The present study was undertaken to establish a distinct relationship between blue crab chitosan (Cs) acetylation degree (AD) and molecular weight (Mw) and its structural features, thermal properties and bioactivity. Therefore, chitosans with different AD were prepared and Cellulase was used to produce Cs derivatives with decreasing Mw. Results clearly display a decrease of the ordered structure of Cs, with the increase of AD and the decrease of Mw. Thermal stability/degradation screening disclose a greater thermal resistance for Cs with lower AD and higher Mw. The anti-adhesive potential of Cs was, additionally, studied, as function of AD and Mw. The effectiveness of Cs in preventing biofilm adhesion was strongly influenced by its AD and Mw, with the lowest inhibition values for higher AD and lower Mw. Interestingly, the effectiveness of $\mathrm{Cs}$ in disrupting pre-formed biofilms increased with decreasing Mw. Moreover, Cs derivatives were found to be advantageously efficient in prolonging human blood clotting times, based on data of activated partial thromboplastin time, Quick time and thrombin time assays, typically for the intrinsic coagulation pathway. Accordingly, depending on the predicted application of Cs, either in food, biomedical and pharmaceutical industries, $\mathrm{AD}$ and $\mathrm{Mw}$ are critical traits to be inevitably reflected on.
\end{abstract}

Keywords: Blue crab chitosan derivatives; Antiadhesive; Anticoagulant. 


\section{Structural features, anti-coagulant and anti-adhesive potentials of

4 Marwa Hamdi ${ }^{a^{*},}$ Rim Nasri ${ }^{\text {a,b }}$, Ikram Ben Amor ${ }^{\mathrm{c}}$, Suming Li ${ }^{\mathrm{d}}$, Jalel Gargouri ${ }^{\mathrm{c}}$, Moncef Nasri ${ }^{\text {a }}$

5 a Laboratory of Enzyme Engineering and Microbiology, University of Sfax, National Engineering School of Sfax, $6 \quad$ B.P. 1173,3038 Sfax, Tunisia.

$7 \quad{ }^{b}$ Higher Institute of Biotechnology of Monastir, University of Monastir, Monastir, Tunisia.

$8 \quad{ }^{c}$ Regional Blood Transfusion Center, Road el-Ain Km 0.5, CP 3003 Sfax, Tunisia.

$9{ }^{\mathrm{d}}$ European Institute of Membranes, UMR CNRS 5635, University of Montpellier, Place Eugene Bataillon, 34095 10 Montpellier Cedex 5, France.

13 * Corresponding author: Marwa Hamdi, Laboratory of Enzyme Engineering and 14 Microbiology, University of Sfax, National Engineering School of Sfax, B.P. 1173, 3038 Sfax, 15 Tunisia. Tel: 21625740373 / 216 54186612; E-mail: marwahamdi50@yahoo.fr. 


\section{Abstract}

The present study was undertaken to establish a distinct relationship between blue crab chitosan (Cs) acetylation degree (AD) and molecular weight $(\mathrm{Mw})$ and its structural features, thermal properties and bioactivity. Therefore, chitosans with different AD were prepared and Cellulase was used to produce Cs derivatives with decreasing Mw. Results clearly display a decrease of the ordered structure of $\mathrm{Cs}$, with the increase of $\mathrm{AD}$ and the decrease of $\mathrm{Mw}$. Thermal stability/degradation screening disclose a greater thermal resistance for Cs with lower $\mathrm{AD}$ and higher Mw. The anti-adhesive potential of Cs was, additionally, studied, as function of $\mathrm{AD}$ and $\mathrm{Mw}$. The effectiveness of $\mathrm{Cs}$ in preventing biofilm adhesion was strongly influenced by its $\mathrm{AD}$ and $\mathrm{Mw}$, with the lowest inhibition values for higher $\mathrm{AD}$ and lower Mw. Interestingly, the effectiveness of $\mathrm{Cs}$ in disrupting pre-formed biofilms increased with decreasing Mw. Moreover, Cs derivatives were found to be advantageously efficient in prolonging human blood clotting times, based on data of activated partial thromboplastin time, Quick time and thrombin time assays, typically for the intrinsic coagulation pathway. Accordingly, depending on the predicted application of $\mathrm{Cs}$, either in food, biomedical and pharmaceutical industries, $\mathrm{AD}$ and Mw are critical traits to be inevitably reflected on.

Keywords: Blue crab chitosan derivatives; Antiadhesive; Anticoagulant. 


\section{Introduction}

Chitosan is a derived amino-polysaccharide, endowed with unique structure and highly multidimensional and sophisticated functionalities [1]. Currently, chitosan is a promising environment friendly biopolymer. Tremendous awareness of using chitosan in life science is increasing due to its advantages, such as availability from renewable agricultural or marine food resources, biocompatibility, biodegradability etc., besides, chitosan ability of being converted to a variety of chemically or enzymatically modified derivatives in a plethora of specific applications [2,3]. Food and nutrition, pharmaceuticals, biotechnology, material science, agriculture and environmental protection, are among the most concerned area [4].

Chitosan is characterized by its molecular weight defined as the number of sugar units per polymer molecule. The molecular weight modulates polymer physico-chemical properties, including viscosity, solubility, adsorption on solids, elasticity, tear strength and biofunctionality [5]. The acetyl content in chitosan defines its acetylation degree. The versatility of chitosan is mainly ascribed to the amino group that correlates with chitosan crystallinity and solubility in acidic solution. Moreover, charge density along the chain and flexibility decrease with the increase in the acetylation degree [6].

In recent years, and to increase the potential applications of chitosan, several technological approaches have been adopted to prepare chitosan chitooligosaccharides or oligomers, including acid hydrolysis [7], enzymatic method [8], ultrasonic degradation [9] and oxidative degradation [10]. Acid hydrolysis is the most commonly used to produce chitosan oligomers. Nevertheless, most of acid hydrolysis products have a low degree of depolymerization, with low production yields [11]. Thus, enzymatic production methods are of great interest in terms of the ability to minimize unwanted chemical changes and promote biological activities. Many specific enzymes, such as chitosanase [12] and non-specific, such 
62 between the physical/chemical features of chitosan, as molecular weight and acetylation degree, on its reactivity and bio-functionality $[6,14]$. Higher viscosity and lower gelation temperatures values were displayed at lower acetylation degrees. Moreover, greater thermal resistance, in terms of higher degradation and transition temperatures were attained for chitosans with lower acetylation degrees. Chitosan-based coatings, with higher acetylation degrees, were found to be less flexible, resistant and transparent. Additionally, due to its biocompatibility and nontoxicity, chitosan has got more attention as effective anti-adhesive agent to prevent various pathogenic bacteria biofilms formation [15]. Indeed, chitosan markedly inhibited the adhesion of all microorganisms tested, and was more efficient in the disruption of pre-formed biofilms. In this aspect, it is of paramount importance to shed light onto the importance of both molecular weight and polymer chemical composition on chitosan bioactivities. Accordingly, the aim of the present work was to contribute to the full understanding of the effect of chitosan acetylation degree and molecular weight on its structural properties and bioactivity, in terms of anti-adhesive and anti-coagulant potentials. To this end, different chitosan derivatives were prepared from blue crab shells chitin, with different acetylation degrees and high, medium and low molecular weights.

\section{Materials and methods}

\subsection{Blue crab chitosan derivatives preparation}

Chitosan (Cs) was prepared from blue crab shells chitin, by $N$-deacetylation using a 12.5 $\mathrm{N} \mathrm{NaOH}$ solution, at a w/v ratio of $1 / 10$ and $140{ }^{\circ} \mathrm{C}$, as previously described [16]. Subsequently, Cs derivatives with different molecular weights (Mw) and acetylation degrees (AD) were prepared [17]. Briefly, to generate Cs with different $\mathrm{AD}$, chitin was treated with $\mathrm{NaOH} 12.5 \mathrm{M}$ at a w/v ratio of $1 / 10$ at $140{ }^{\circ} \mathrm{C}$, for $2 \mathrm{~h}, 3 \mathrm{~h}$ and $5 \mathrm{~h}$ and produced $\mathrm{Cs}$ were referred as CsI, CsII and CsIII, and corresponding AD were determined based on the nuclear 
magnetic resonance analysis. Subsequently, to produce Cs with different Mw, Cs were

87 hydrolyzed with Cellulase (10 U/g chitosan) in $0.5 \mathrm{~N}$ acetate-bicarbonate buffer (pH 5.2) at 55 referred as Cs-1 and Cs-3, respectively. Size exclusion chromatography was used to characterize the obtained Cs average Mw.

\subsection{Blue crab chitosan derivatives purification}

Cs were purified based on the method described by Qian \& Glanville [19]. Thus, crude Cs $(6 \mathrm{~g})$ was dissolved in $600 \mathrm{ml}$ of $\mathrm{HCl} 0.1 \mathrm{M}$ under stirring overnight at $40{ }^{\circ} \mathrm{C}$, and subsequently, vacuum filtered. Cs was, thereafter, precipitated with $\mathrm{NaOH} 0.5 \mathrm{M}$ under continuous stirring until $\sim \mathrm{pH} 8.5$. Afterward, a volume $(6 \mathrm{ml})$ of sodium dodecyl sulfate $(10 \%$, w/v) was added to the mixture and heated at $95{ }^{\circ} \mathrm{C}$ for 5 min. After cooling, $\mathrm{NaOH} 0.5 \mathrm{M}$ was used to adjust the $\mathrm{pH}$ to 10.0. The mixture was vacuum filtered and the hydrated Cs was washed 5 times with $600 \mathrm{ml}$ of deionized water at $40{ }^{\circ} \mathrm{C}$, lyophilized, milled to powder and then sieved.

\subsection{Chitosan derivatives characterization}

Chitosans ADs were determined by using solid-state nuclear magnetic resonance $\left({ }^{13} \mathrm{C}\right.$ CP/MAS NMR) spectroscopy (Varian VMMRS300 spectrometer). A frequency of $300 \mathrm{MHz}$, an acquisition time of $40 \mathrm{~ms}$, a contact time of $1 \mathrm{~ms}$ and a $4 \mathrm{~s}$ repetition time were applied.

Based on the area of the resonance of the methyl group carbon compared to the average area of the resonances of the carbon atoms of glycosyl ring, ADs of the samples were calculated using the following relationship [20]:

$$
\mathrm{AD}(\%)=\frac{\mathrm{I}_{\mathrm{CH}_{3}}}{(\mathrm{I}[\mathrm{C} 1]+\mathrm{I}[\mathrm{C} 2]+\mathrm{I}[\mathrm{C} 3]+\mathrm{I}[\mathrm{C} 4]+\mathrm{I}[\mathrm{C} 5]+\mathrm{I}[\mathrm{C} 6]) / 6} \times 100
$$
where $I$ is the area of the particular resonance peaks allowing to get $\mathrm{AD} \%$ with $5 \%$ precision. 
Steric Exclusion Chromatography (SEC) was performed using multi-detector equipment

with a differential refractometer, a multiangle laser light scattering detector and a viscometer from WYATT Technology (DAWN DSP-F). Acetic acid $0.3 \mathrm{M} /$ sodium acetate $0.2 \mathrm{M}(\mathrm{pH}=$ 4.5) was adopted as solvent (at $25 \pm 2{ }^{\circ} \mathrm{C}$ ). TSK Gel GMPWXL column type was used and a flow of $0.4 \mathrm{ml} / \mathrm{min}$ was adopted. The increment of refractive index $\mathrm{dn} / \mathrm{dc}$, determined for the different $\mathrm{AD}$ values in the same solvent, was 0.190 [21]. Resulted chromatograms were analyzed with ASTRA 6.1.2 (WYATT Technology) software and weight-average molecular weights $\left(\mathrm{g} \mathrm{mol}^{-1}\right)$, were determined.

\subsection{Spectroscopic analysis}

To investigate the structural characteristics of the prepared Cs, X-ray diffraction (XRD) patterns were recorded using an X-ray diffractometer (D8, Advance Bruker XRD diffractometer, Germany). $\mathrm{Ni}$-filtered $\mathrm{Cu} \mathrm{K \alpha}$ radiation $\left(\mathrm{k}=1.5406^{\circ} \mathrm{A}\right)$ was used to record the X-ray powder patterns. The relative intensity was recorded in the scattering range $2 \theta$ of $5-50^{\circ}$ with a step size of $0.02^{\circ}$ and a counting time of $5 \mathrm{~s} / \mathrm{step}$, with an error of $\pm 1^{\circ}$. The crystalline index value (CrI) was calculated according to the following formula [22]:

$$
\mathrm{CrI}_{110}(\%)=\frac{\mathrm{I}_{110}-\mathrm{I}_{\mathrm{am}}}{\mathrm{I}_{110}} \times 100
$$

where $\mathrm{I}_{110}$ is the maximum intensity at $2 \theta \approx 20^{\circ}$ and $\mathrm{I}_{\mathrm{am}}$ is the intensity of amorphous diffraction at $2 \theta \approx 10^{\circ}$.

\subsection{Chitosan derivatives thermal properties analyses}

\subsubsection{Thermogravimetric analysis}

Thermal stability of Cs powders was studied using thermogravimetric analysis (TGA Q500 High Resolution, TA Instruments), operating under nitrogen flow. The thermogravimetric analysis is based on the mass change of a sample as a function of temperature augmentation and a thermogram, showing the progressive change in mass in percentage (\%) as a function of 
temperature, is recorded. Cs powders were heated from 25 to $800{ }^{\circ} \mathrm{C}$ at a heating rate of 20 ${ }^{\circ} \mathrm{C} / \mathrm{min}$. The weight of Cs powder samples, initially about $4 \mathrm{mg}$, was constantly measured with an accuracy of $0.01 \mathrm{mg}$.

\subsubsection{Differential scanning calorimetry}

Differential Scanning Calorimeter (Modulated DSC Q20, TA Instruments), equipped with a liquid nitrogen cooling system, was used to further investigate the thermal properties of Cs, allowing the estimation of melting and crystallization point, as well as the glass transition of the macromolecular materials. Cs samples were accurately weighed into sealed aluminum pans. An empty capsule serves as an inert reference and the apparatus was calibrated using indium. The thermal profile was analyzed in a temperature range of $0-225{ }^{\circ} \mathrm{C}$, at a heating rate scan of $10{ }^{\circ} \mathrm{C} / \mathrm{min}$, under nitrogen flow rate of $50 \mathrm{ml} / \mathrm{min}$. Thermograms were then analyzed by using TA Universal V4.5A software.

\subsection{Influence of $A D$ and $M w$ on blue crab chitosan derivatives anti-adhesive potential}

The ability of Cs derivatives, with different $\mathrm{AD}$ and $\mathrm{Mw}$, to hinder microbial adhesion or to remove pre-formed biofilms, through surface pre-treatment and post-treatment, respectively, were tested according to the modified method of O'Toole [23].

Regarding surface pre-treatment, $200 \mu \mathrm{l}$ of Cs $(0.01$ to $12.5 \mathrm{mg} / \mathrm{ml}$ dissolved in phosphate buffered saline (PBS) pH 7.2) were transferred into the wells of a microplate. After incubation for $6 \mathrm{~h}$ at room temperature $\left(25^{\circ} \mathrm{C}\right)$, plates were washed twice with PBS. For biofilm formation, Escherichia coli (ATCC 25922) was chosen as microorganism model [16] and strains were grown overnight in Muller Hinton broth (MHB). A volume of $200 \mu \mathrm{l}$ of 1/50 dilution in the 153 medium proposed by O'Toole [23] (g/l: glucose, 2; casamino acids, 5; $\mathrm{KH}_{2} \mathrm{PO}_{4}, 3 ; \mathrm{K}_{2} \mathrm{HPO}_{4}, 7$; $\left.154\left(\mathrm{NH}_{4}\right)_{2} \mathrm{SO}_{4}, 2 ; \mathrm{MgSO}_{4} .7 \mathrm{H}_{2} \mathrm{O}, 0.12\right)$ were putted in the microplate wells, and incubated for $20 \mathrm{~h}$ at $37^{\circ} \mathrm{C}$. Wells were washed three times with distilled water to remove unattached cells and the 
adherent microorganisms were fixed for $15 \mathrm{~min}$ with pure methanol $(150 \mu \mathrm{l})$, and stained for

15720 min with crystal violet (1\%). After washing with water and drying, the stains in the wells 158 were diluted with $200 \mu 1$ of acetic acid (33\%). Control wells contained only PBS or Cs solution. 159 Subsequently, the absorbance was determined at $595 \mathrm{~nm}$, and percentages of microbial adhesion 160 inhibition were estimated as follow:

$$
\text { Adhesion inhibition }(\%)=\left(1-\frac{\mathrm{A}_{\mathrm{C}}}{\mathrm{A}_{\mathrm{O}}}\right) \times 100
$$

where $A_{C}$ corresponds to the absorbance of the well with $C$ s at concentration $C$, and $A_{O}$ the absorbance of the control well (without Cs).

For the post-treatment with Cs, wells were first incubated, with $200 \mu \mathrm{l}$ of bacterial suspension prepared as mentioned above, for $20 \mathrm{~h}$ at $37^{\circ} \mathrm{C}$. Afterward, wells were washed three times with distilled water to remove the unattached microbial cells. Then, $200 \mu 1$ of Cs solution were added to each well and incubated at $25{ }^{\circ} \mathrm{C}$ for $6 \mathrm{~h}$. After incubation, wells were treated as above mentioned and adhesion inhibition was calculated.

\subsection{Anticoagulant behavior of chitosan derivatives as affected by its AD and Mw}

Plasma-based coagulation time was studied based on the activated partial thromboplastin time (APTT), the Quick time (QT) and the thrombin time (TT) in vitro assays, using a semiautomatic line STA (Diagnostica Stago).

\section{$173 \quad$ 2.7.1. Activated partial thromboplastin time}

The APTT was estimated on a mixture of $45 \mu \mathrm{l}$ of normal citrated platelet poor plasma (healthy adult subjects not receiving drugs that interfere with coagulation), $5 \mu 1$ of Cs and Cs derivatives -solutions at different concentrations and $50 \mu \mathrm{l}$ of the APTT reagent (CK-PREST). The mixture was pre-incubated at $37^{\circ} \mathrm{C}$ for $3 \mathrm{~min}$, then the reaction was initiated by the addition of $100 \mu \mathrm{l}$ of $\mathrm{CaCl}_{2}(0.025 \mathrm{M})$, previously heated to $37^{\circ} \mathrm{C}$ (coagulation intrinsic path). The 
coagulation time was expressed in seconds, based on the method reported by Langdell, Wagner \& Brinkhous [24].

\subsubsection{Quick time}

For the QT, the test consists of the comparison of the coagulation time of citrated plasma sample to be studied with a normal reference plasma), in the presence of an excess of calcified thromboplastin [25]. Thus, in a microplate reader, at $37^{\circ} \mathrm{C}$, a reaction mixture was prepared containing $45 \mu \mathrm{l}$ of plasma, $5 \mu \mathrm{l}$ of the $\mathrm{Cs}$ and Cs derivatives solutions at different concentrations and a volume of $100 \mu 1$ of calcified thromboplastin (Neoplastin ${ }^{\circledR}$ Diagnostica stago, tissue activating factor of the extrinsic path). The coagulation time, subsequently to mixing, was expressed in seconds.

\subsubsection{Thrombin time}

The TT allows to explore the common path of coagulation, by measuring the coagulation time of a citrated plasma in the presence of a known amount of thrombin and calcium. Thus, 5 $\mu \mathrm{l}$ of $\mathrm{Cs}$ and Cs derivatives solutions at different concentrations were mixed with $45 \mu \mathrm{l}$ of platelet depleted and decalcified plasma, previously heated to $37{ }^{\circ} \mathrm{C}$ for $3 \mathrm{~min}$ (or $0.4 \%$ fibrinogen solution in $0.05 \mathrm{mM}$ of Tris- $\mathrm{HCl}$ buffer $(\mathrm{pH} 7.2)$ containing $0.12 \mathrm{mM}$ of $\mathrm{NaCl}$ ). After addition of $100 \mu \mathrm{l}$ of calcified thrombin (12 UI) prepared in the same buffer (initiation of the reaction), the coagulation time was measured and expressed in seconds [25].

\section{$197 \quad 2.8$. Statistical analysis}

All experiments were carried out in triplicate, and average values with standard deviation are reported. Mean separation and significance were analyzed using the SPSS software package ver. 17.0 professional edition (SPSS, Inc., Chicago, IL, USA) using ANOVA analysis. Differences were considered significant at $\mathrm{p}<0.05$. 


\section{Results and Discussion}

\subsection{Blue crab chitosan derivatives preparation and characterization}

Cs was initially prepared by $N$-deacetylation of blue crab shells chitin, with an average extraction yield of approximatively $70 \%$ (chitin dry weight basis) and typically characteristic of $\alpha$-chitosan [16]. Accordingly, Cs derivatives with different AD and Mw were prepared by increasing $N$-deacetylation reaction times followed by enzymatic hydrolysis with Cellulase.

Considering the obtained ${ }^{13} \mathrm{C}$ NMR spectra (Fig. 1), AD of prepared Cs derivatives was determined and results are reported in Table 1. As the duration of $N$-deacetylation increased, the AD significantly decreased, as evidenced by a gradually negligible detected signals for $\mathrm{CH}_{3}$ and $\mathrm{C}=\mathrm{O}$ groups. $\mathrm{AD}$ of the prepared $\mathrm{Cs}$ derivatives was found to be ranging from $17 \%$ (undigested CsI) to $8 \%$ (undigested CsIII). Furthermore, the increase in the enzymatic depolymerization duration was found not significantly affecting the $\mathrm{AD}$ of blue crab Cs derivatives.

The estimation of average Mw by steric exclusion chromatography (Table 1) reveal the effectiveness of Cs depolymerization using Cellulase to produce Cs derivatives with decreasing average Mw. Results reveal that Cs derivatives, recovered at different hydrolysis incubation times, exhibited an average Mw of 17800,59270 and $78430 \mathrm{~g} \mathrm{~mol}^{-1}$, for CsI-1, CsII-1 and CsIII-1, respectively, and 10 440, 18540 and $16040 \mathrm{~g} \mathrm{~mol}^{-1}$ for CsI-3, CsII-3 and CsIII-3, respectively (Table 1). Average Mw of 125600,118900 and $115000 \mathrm{~g} \mathrm{~mol}^{-1}$ were reached for undigested CsI, undigested CsII and undigested CsIII, respectively.

X-ray diffraction patterns for the prepared Cs, investigated between 5 and $50^{\circ}$ of $2 \theta$, display typical fingerprints of semi-crystalline chitosan, with strong reflections at around $2 \theta=$ $10.8^{\circ}$ and $2 \theta=20.1^{\circ}$ (Fig. 2), due to the crystalline chitosan structure [16]. Based on the X-ray diffractograms, the crystallinity index $(\mathrm{CrI})$ were further determined and results show an increase in Cs crystallinity with the decrease of its $\mathrm{AD}$. In fact, $\mathrm{CrI}$ of $23 \%$ and $29 \%$ were 
obtained with ADs of 17\% (undigested CsI) and 8\% (undigested CsIII), respectively. Moreover, the decrease of Cs Mw was reflected by a decrease of its ordered structure, as evidenced by a drop in the reflection around $2 \theta=20.1^{\circ}$. For example, with an $\mathrm{AD}$ of $8 \%$ (undigested CsIII), after digestion with Cellulase, reached CrI values were of $20 \%$ and $1 \%$ for Mws of $78000 \mathrm{~g}$ $\mathrm{mol}^{-1}$ (CsIII-1) and $16000 \mathrm{~g} \mathrm{~mol}^{-1}$ (CsIII-3) vs. $29 \%$ for $115000 \mathrm{~g} \mathrm{~mol}^{-1}$ (undigested CsIII), respectively. This increase in the disordered structure with the increase of the AD and the decrease of the Mw could be explained by a transition from a crystalline structure to an amorphous state during the enzymatic depolymerization process, due to the arrangement of the polysaccharide chain as well as the intermolecular hydrogen bonds, compared to the free amine forms (low acetylation degree and high molecular weight) [26,27].

\subsection{Thermal behavior and stability of blue crab chitosans}

Thermal stability/degradation behavior of Cs, with respect to its Mw, was further studied, 239 in the present work, and results in terms of TGA and DSC thermograms, are reported. Thermal 240 features, in terms of degradation and glass transition ( $\mathrm{Tg}$ ) temperatures, of chitosan were 241 previously studied and found to be strongly dependent on its $A D$, where greater thermal 242 resistance was noted for $\mathrm{Cs}$ with lower $\mathrm{AD}$, in terms of significantly higher degradation 243 temperature and improved $\mathrm{Tg}$ values [28]. Consequently, it seems to be very interesting to 244 further verify the combined effects of $\mathrm{Cs} \mathrm{AD}$ and $\mathrm{Mw}$ on its thermal degradation/stability 245 behavior.

246 Based on data from the obtained TGA thermograms (Fig. 3A), the thermal decomposition 247 profiles of the overall Cs exhibited a similar weight loss process in the temperature range of $24820-800{ }^{\circ} \mathrm{C}$, indicating the polymer pyrolysis, and characterized by two major phases, typical 249 fingerprint of Cs thermal decomposition [14]. The thermal decomposition data, considering the 250 derivate (DTG) thermograms (Fig. 3B), in terms of the corresponding degradation temperatures 251 (Td: onset temperature of degradation, Tmax: maximum degradation temperature and Tf: 
252 temperature of the end of degradation), the weight loss $(\Delta \mathbf{w})$ and the residue $(\mathbf{R})$, were estimated

(Table 2).

The first phase, apparently resulted from the evaporation of adsorbed water by Cs, corresponded to a weight loss of 6-8\% at a Td 1 range from $41-58{ }^{\circ} \mathrm{C}$ to $\mathrm{Tf} 1$ range of $142-267$ ${ }^{\circ} \mathrm{C}$, reaching its maximum mainly below $150{ }^{\circ} \mathrm{C}$, depending on $\mathrm{Cs}$ derivatives $\mathrm{Mw}$. For example, regarding an AD of $8 \%$, Tmax 1 values dropped to $143{ }^{\circ} \mathrm{C}$ and $123{ }^{\circ} \mathrm{C}$ for CsIII- 1 and CsIII-3, respectively, vs. $267{ }^{\circ} \mathrm{C}$ for undigested CsIII. The same tendency was noted with CsII (AD of $13 \%)$ and $\mathrm{CsI}(\mathrm{AD}$ of $17 \%)$.

In the range of the second phase of Cs pyrolysis process, corresponding to the major loss of weight, three major steps could be defined: until $300{ }^{\circ} \mathrm{C}$ (ascribed to the decomposition of the D-glucosamine units), from $300{ }^{\circ} \mathrm{C}$ to $\sim 500{ }^{\circ} \mathrm{C}$, (attributed to the $\mathrm{N}$-acetyl- $D$-glucosamine units depolymerization) and above $\sim 600{ }^{\circ} \mathrm{C}$ (due to residual decomposition reactions). Peaks located at Tmax 2 of 460, 306 and $295{ }^{\circ} \mathrm{C}$, were found for the CsI-0, CsI-1 and CsI-3, respectively, whereas those found at 474,402 and $355{ }^{\circ} \mathrm{C}$ were related to the CsIII-0, CsIII-1 and CsIII-3, respectively (Table 2). Moreover, the highest weight loss ( $\Delta \mathrm{w}$ ) of $64 \%$ was detected with CsI-3, exhibiting the highest AD of $17 \%$ and the lowest average Mw of $10440 \mathrm{~g}$ $\mathrm{mol}^{-1}$. Nonetheless, the lowest $\Delta \mathrm{w}$ of $56 \%$ was revealed by the undigested CsIII (AD of $8 \%$ and Mw of $115000 \mathrm{~g} \mathrm{~mol}^{-1}$ ) and 57\% with the undigested CsII (AD of 13\% and Mw of $118900 \mathrm{~g}$ $\left.\mathrm{mol}^{-1}\right)$. Polymers pyrolysis temperature differences were mainly assigned to the macromolecular interaction, in line with the crystallinity index values [6].

Additionally, residual mass (R) was found to decrease with the decrease of the Cs Mw, with values of 28\% (CsI-3), 30\% (CsI-1) and 34\% (undigested CsI). Considering CsII, R values 274 of $29 \%, 31 \%$ and $36 \%$ were reached for the CsII-3, CsII-1 and undigested CsII, respectively. R 275 values of $38 \%, 33 \%$ and $31 \%$ were noted for undigested CsIII, CsIII-1 and CsIII-3, respectively 
277 disproportionate with its AD and positively correlated to its Mw. Therefore, AD and Mw could

278 be considered as extremely important Cs's structural traits, modulating its macromolecular 279 chains properties and thereby, Cs solubility, macromolecular chains flexibility and 280 conformation [29].

In another aspect of the study of $\mathrm{Cs}$ thermal properties dependence on its $\mathrm{Mw}$, considering DSC analysis, the glass transition temperature (Tg) was determined (Table 2). It was found that the more the $\mathrm{Cs} \mathrm{Mw}$ was higher, the more was its thermal stability. In this context, Tg values of $202{ }^{\circ} \mathrm{C}, 188^{\circ} \mathrm{C}, 173{ }^{\circ} \mathrm{C}, 191{ }^{\circ} \mathrm{C}, 172{ }^{\circ} \mathrm{C}$, and $157^{\circ} \mathrm{C}$ were noted for undigested CsIII, CsIII1, CsIII-3, undigested CsII, CsII-1 and CsII-3, respectively. Nevertheless, for CsI group, Tg values decreased further to $166^{\circ} \mathrm{C}$ and $142{ }^{\circ} \mathrm{C}$, for CsI-1 and CsI-3, respectively, vs. $188^{\circ} \mathrm{C}$ for undigested CsI. Accordingly, besides Cs AD [28], Mw affected strongly its glass transition temperature, and subsequently, Cs thermal resistance, in the same line of the TGA findings.

\subsection{Blue crab chitosans anti-adhesive behavior as influenced by its AD and Mw}

Among the most challenging problems in food industries and hospitals, finding an alternative and effective strategy to hinder or to remove biofilm formation, is a public concern and has broadly attracted wide attention [30]. Microbial adhesion could be considered as the optimal time for anti-adhesive compounds action. In fact, in utmost environments, the prevail mode of growth for microbes is living as biofilm, defined as biotic or abiotic surfaces adhering communities of microbes. Individual bacteria adhesion to a surface is the initial phase of biofilm development to establish the complex community architecture of a biofilm [31]. Biosurfactants have been reported to be powerful inhibitors and disruptors of microbial adhesion and biofilm formation [32]. Moreover, the role of chitosan in microbial anti-adhesion was, previously, investigated and results reveal that adsorption of chitosan to solid surfaces can be an effective strategy to reduce microbial adhesion, besides, combating pathogenic micro-organisms colonization [16]. Thus, to have a better understanding of chitosan anti-adhesive mechanism, it 
seems to be compelling to study the effects of Cs AD and Mw on its anti-adhesive and disruptive activities.

\subsubsection{Anti-adhesive activities of Cs derivatives}

The anti-adhesive activity was investigated, through the pretreatment of polystyrene surfaces with Cs derivatives solutions, against E. coli, as microbe model. As it can be seen in

Fig. 3A, the pretreatment of polystyrene surfaces with Cs and its derivatives revealed clearly an anti-adhesive effect against $E$. coli biofilm formation in a Cs concentration-dependent manner, i.e. higher inhibition values were reached at higher Cs concentrations. For example, subsequently to the surface treatment with the undigested CsIII, the bacterial adhesion inhibition decreased from more than $62 \%$ to about $16 \%$, when Cs concentration decreased from $12.5 \mathrm{mg} \mathrm{ml}^{-1}$ to $0.01 \mathrm{mg} \mathrm{ml}^{-1}$. The same tendency was noted with the other tested Cs derivatives. Therefore, even at low concentration, Cs derivatives were very active and a diminution in bacterial adhesion was detected. The inhibition of biofilm formation could be ascribed to Cs and its derivatives to modify surface (coated with Cs molecules) hydrophobicity, interfering in the microbial adhesion and desorption process [33]. Additionally, previous reports have shown that chitosan has bactericidal effects [34]. Our data are in agreement with previous results suggesting that, at higher concentrations, the polystyrene surface became covered by Cs 319 molecules that were adsorbed on bacterial cells to a higher degree due to the increase in the 320 positive charge [35].

321 At the studied concentrations, the adhesion of E. coli was still limited by Cs and its 322 derivatives, to variable extend, depending on Cs $\mathrm{AD}$ and $\mathrm{Mw}$ (Fig. 3A). The highest anti323 adhesive effect was observed with undigested CsIII (AD of $8 \%$ ), with an inhibition percentage 324 of about $63 \%$, at a concentration of $1.25 \%(\mathrm{w} / \mathrm{v})$, which decreased concomitantly with the 325 increase of the $\mathrm{AD}$, reaching $60 \%$ and $57 \%$ for undigested $\mathrm{CsII}$ (AD of 13\%) and undigested 326 CsI (AD of 17\%). The same tendency was noted with the prepared Cs derivatives, 
independently of their Mw, where their anti-adhesive effects were negatively correlated with their AD and higher anti-adhesive effects were perceived with lower AD Cs derivatives. These results depict that the anti-adhesion activity of the surfaces coated with high $\mathrm{AD}(17 \%) \mathrm{Cs}$ derivatives was significantly lower compared to the low AD (8\%) Cs derivatives-coated surfaces by reason of the effective antibacterial activity of Cs derivatives. Higher amine groups, and thereby lower AD, allowed higher positive charge density, which confers stronger antibacterial activity against $E$. coli $[34,36]$.

Moreover, the inhibitory effect was found to be dependent on the Cs Mw (Fig. 3A). Based on the obtained data, for the same $\mathrm{AD}$, the inhibition of $E$. coli adhesion, subsequently to polystyrene surfaces treatment with Cs, decreased with the decrease of the Mw. For example, for an $\mathrm{AD}$ of $8 \%$ (CsIII), the inhibition of adhesion diminished from $63 \%$ for the undigested CsIII to $57 \%$ and $54 \%$ for CsIII-1 and CsIII-3, respectively, at a concentration of $1.25 \%(\mathrm{w} / \mathrm{v})$. Inhibition values of $57 \%$ and $49 \%$ were noted with undigested CsI and CsI-1, respectively, vs. $36 \%$ for CsI-3. This finding could be mostly attributed to the drop of Cs solutions' viscosity, after digestion with cellulase, generating Cs derivatives with low Mw, and further explained by the decrease in positive charge density of Cs. Hence, our results suggest a positive correlation between the adsorbed $\mathrm{Cs}$ and the efficiency to reduce the adhesion stage of $E$. coli, therefore, the further development of biofilms can be blocked. Otherwise, bacterial adhesion was found to be depended not only on bacterial charge and surface type, but also, on Cs charge interfering in its effects $[34,35,37]$. This phenomenon confirmed our findings that during the process of bacterial growth, low Mw Cs derivatives exhibited weak bactericidal effect.

\subsubsection{Pre-formed biofilm disruption effects (post-treatment)}

Besides the inhibition of biofilms adhesion (initial stage of biofilm formation), the disruption of pre-formed biofilms, which consists in removing the attached microorganisms 
351 from the biotic or abiotic surface after biofilm formation, is another interesting phenomenon to

be studied.

As illustrated in Fig. 3B, the efficacy of biofilm disruption decreased with decreasing Cs derivatives concentration from 12.5 to $0.01 \mathrm{mg} \mathrm{ml}^{-1}$, and interestingly the percentages of disruption remained nearly constant above a concentration of $0.2 \mathrm{mg} \mathrm{ml}^{-1} \mathrm{Cs}$, independently of Cs $\mathrm{AD}$ and $\mathrm{Mw}$. Indeed, Cs was probably efficient in penetration and adsorption at the interface between the solid surface and the pre-formed biofilm, interfering with surface adhesion, to promote its detachment [15].

In line with the pre-treatment test (adhesion inhibition), disruption of pre-formed biofilm values increased with the decrease of $\mathrm{Cs} \mathrm{AD}$, the maximum disruption was observed with undigested CsIII (91\%), followed by undigested CsII (85\%) and undigested CsI (76\%). This finding could be related to high surface activity of $\mathrm{Cs}$ with lower $\mathrm{AD}$, promoting the reduction of interfacial tension [38]. Otherwise, Cs with lower AD and high Mw could mold, around the cells, an impermeable layer, delaying afterward the channels and preventing essential nutrients transport. As a result, the cell wall would be destabilized, ultimately cell death [35].

Conversely, for the same $\mathrm{AD}$, the effectiveness of Cs in disrupting pre-formed biofilm (post-treatment) increased with decreasing its Mw. For example, disruption values of 91\%, 94\% and 97\% were reached after treatment with undigested CsIII, CsIII-1 and CsIII-3, respectively. Likewise, undigested CsII, CsII-1 and CsII-3 allowed the elimination of 84\%, 88\% and 91\% of 370 the pre-formed biofilms, respectively (Fig. 3B). This effect may be explained by the fact that 371 at lower Mw, Cs infiltration and adsorption at the interface between the solid surface and the 372 adherent bacteria forming a biofilm are easier and more pronounced, allowing derivatives to 373 exert their disturbing effect, and thereby, the death of bacteria [15,39].

The present study is opportune to have a better and extended understanding of the 375 mechanisms of inhibition of biofilm formation, whether by adhesion inhibition or by disruption 
of pre-formed biofilms, testifying the effectiveness of Cs and Cs derivatives as attractive

377 alternatives for bacterial pathogens control in food and hospital fields. AD and Mw strongly units of heparin) [44].

\subsection{Study of blue crab chitosan and its derivatives anti-coagulant activity}

Coagulation is the haemostasis second step that involves a cascade of enzymatic reactions including clotting factors. coagulation intervenes in platelet aggregate, obtained at the end of primary haemostasis, promoting bleeding breaking. Coagulation of human blood cascade involves two intrinsic and extrinsic pathways, that joins at the stage of factor $\mathrm{Xa}$ (FXa) formation by factors IXa (FIXa) and FVIIa, respectively. The thrombin conversion of soluble fibrinogen into fibrin filaments consists of the coagulation ultimate step. In the case of an inequity in this equilibrium, either bleeding or thrombus formation occur. Several of critical cardiovascular diseases result from fibrin accumulation in blood vessels, interfering with blood flow [40]. Multitude of drugs have been developed for the treatment of blood clots and thereby, preventing the damage they cause, behaving as blood clotting power thinner and clot growth preventor. Unfractionated heparin, low molecular weight heparin, and warfarin are the most common anti-coagulants used. Currently, researchers are prompted to strive new and better anti-coagulants with reduced side risks [41-43].

Chitosan and chitosan derivatives are reported as anti-coagulants in literature, owing to their structural similarity with heparin ( $\mathrm{N}$-acetylglucosamine and iduronic acids are constituent 
As a second promising application of blue crab Cs, the anti-coagulant activity of the prepared Cs derivatives, with different $\mathrm{AD}$ and $\mathrm{Mw}$, was evaluated, by the classical coagulation assays of APTT, QT and TT. APTT is the measurement of the activity of all coagulation factors in the intrinsic pathway, while QT allow the screening of the activity of the extrinsic pathway. TT measurement reflects the investigation of fibrin polymerization process determining the fibrin formation time from fibrinogen after known amounts of thrombin addition to the plasma sample.

The results of the anti-coagulant activity of the different types of Cs are listed in Table 3. Regarding the control (distilled water), APTT, QT and TT of $31,2 \mathrm{~s}, 14,8 \mathrm{~s}$ and 14,4 s, respectively, were reached. Above a concentration of $12.5 \mu \mathrm{g} / \mathrm{ml}$ plasma, all Cs derivatives were endowed with an anti-coagulant potential, since APTT, QT and TT times were effectively prolonged compared to distilled water in a Cs dose-dependent manner. For example, the APTT and QT, prolonged from $74.7 \mathrm{~s}$ to $>120 \mathrm{~s}$ and from $15.7 \mathrm{~s}$ to $19.1 \mathrm{~s}$, respectively, when the concentration of undigested CsIII in the reaction mixture increased from $12.5 \mu \mathrm{g} / \mathrm{ml}$ to 25 $\mu \mathrm{g} / \mathrm{ml}$. The TT increased from $15.9 \mathrm{~s}$ to 16.7 in the presence of $12.5 \mu \mathrm{g} / \mathrm{ml}$ and $25 \mu \mathrm{g} / \mathrm{ml}$ of undigested CsIII, respectively. Results of APTT and TT of heparin sodium were reported to reach $79.7 \mathrm{~s}$ and $51.2 \mathrm{~s}$ at $14 \mu \mathrm{g} / \mathrm{ml}$ plasma, respectively [45]. APTT and QT assay of heparin sulphate showed $61.2 \mathrm{~s}$ and $31.4 \mathrm{~s}$ at the concentration of $50 \mu \mathrm{g} / \mathrm{ml}$ plasma, respectively [46]. However, considering their $\mathrm{AD}$ and average $\mathrm{Mw}$, the different types of $\mathrm{Cs}$ derivatives displayed diverse anti-coagulant activity patterns.

Considering the AD of the different types of tested CCB derivatives (Table 3), APTT and QT values increased with the decrease of the AD $(\mathrm{p}<0.05)$. Indeed, undigested CsIII allowed the most substantial prolongation of APTT by more than 2-folds $(74.7 \mathrm{~s})$, compared with that obtained with distilled water (31.2 s), when added at a concentration of $12.5 \mu \mathrm{g} / \mathrm{ml}$ plasma in the reaction medium. QT screening displayed the same trend. Indeed, values were, similarly, 
improved with the decrease of derivatives $A D$, reaching 17 s, $18.1 \mathrm{~s}$ and $19.1 \mathrm{~s}$, with addition of undigested CsIII, undigested CsII and undigested CsI, respectively, at a concentration of 25 $\mu \mathrm{g} / \mathrm{ml}$ plasma, $v s$. QT of $14.8 \mathrm{~s}$ with distilled water.

As shown in Table 3, results of the present study reveal that the anti-coagulant potential, in terms of APTT and QT, was interestingly more marked with low Mw Cs derivatives. In fact, at a concentration of $12.5 \mu \mathrm{g} / \mathrm{ml}$ plasma, APTT of undigested CsIII (74.7 s) was lower than those obtained with CsIII-1 and CsIII-3, with values of $93.2 \mathrm{~s}$ and $>120 \mathrm{~s}$, respectively. The same tendency was noted with the other derivatives (undigested and Cellulase-treated CsII and CsI), with APTT that increased significantly with the decrease in the Mw of Cs derivatives $(p<0.05)$. These findings were further confirmed by the study of Cs derivatives activity in the extrinsic coagulation pathway (QT), where the lower the Mw of the derivatives was, the better was their anti-coagulant activity $(\mathrm{p}<0.05)$. The highest times were, therefore, reached with CsI3 (19.7 s), CsII-3 (20.5 s) and CsIII-3 (21.2 s), at a concentration of $25 \mu \mathrm{g} / \mathrm{ml}$ of plasma, probably correlated with the higher water solubility of the CCB derivatives prepared, having low DA and Mw [47]. Additionally, Cs derivatives with the lowest AD could have the greatest degree of similarity with regards to heparin structure. The positively charged groups $-\mathrm{NH}_{3}{ }^{+}$ increase the adsorption of proteins through the electrostatic effect, which increases the activation of intrinsic cascade [48].

Conversely, the screening of the effects of Cs AD and Mw on its anti-coagulant behavior, considering the TT that provides information about the evaluation of the common pathway of coagulation, reveal that clotting time decreased with the decrease of $\mathrm{AD}$ and Mw (Table 3). Subsequently to the addition of $25 \mu \mathrm{g} / \mathrm{ml}$ plasma, in the reaction mixture, the highest TT values 448 were attained with the undigested CsI (21.3 s), undigested CsII (19 s) and undigested CsIII 449 (16.7 s), followed by CsI-1 (19.3 s), CsII-1 (17.9 s) and CsIII-1 (16.5 s). The lowest TT 450 prolongation values were reached in the presence of CsI-3 (17.3 s), CsII-3 (16.8 s) and CsIII-3 
(16.3 s). This finding could be ascribed to lower complex-forming ability of Cs derivatives (lower Mw) with the blood components, such as factor Xa [44]. A previous study showed that the higher molecular weight fractions of low molecular weight chitosan polysulfate exhibited the greatest anticoagulant activity as assessed using the TT assay [49].

Data of the present study proposed that blue crab chitosan and its derivatives affected mainly the intrinsic pathway and have a potential anti-coagulant capacity. Consequently, further work is in progress to establish clear relationship between $\mathrm{Mw}$ and $\mathrm{AD}$ and the anti-coagulant activity and to understand their exact mechanism of action.

\section{Conclusion}

In the present work, the effects of $\mathrm{AD}$ and average $\mathrm{Mw}$ of $\mathrm{Cs}$ derivatives on their biofunctionalities were investigated. Data reveal that Cs crystallinity decreased with the increase of its $\mathrm{AD}$ and the decrease of its Mw, displaying more disordered structure. Thermal stability and degradation behavior, in terms of degradation and transition temperatures, were improved with lower AD. Higher thermal stability was, moreover, noted with higher Mw Cs derivatives. Advantageously, Cs derivatives would be potential alternative for bacterial pathogens control in food industry, since they were found to display anti-adhesive and pre-formed biofilms disruptive effects. The highest anti-adhesive effect was observed with lower AD and higher Mw Cs derivatives. Cs derivatives, and particularly those with lower Mw, were found more efficient in disrupting pre-formed biofilms. Scanning electron microscopy, confocal laser scanning microscopy, analysis of the exopolysaccharide and biofilms metabolic activity screening could be very useful tools to have a better understanding of the relationship between $\mathrm{Mw}$ and $\mathrm{AD}$ and the anti-adhesive activity and to establish their exact mechanism of action. Additionally, Cs derivatives were found to be effectively endowed with anti-coagulant activity, mainly for the intrinsic coagulation pathway, to be applied in biomedical and pharmaceutical 
4

industries. However, no clear relationship, between $\mathrm{AD}$ and $\mathrm{Mw}$ and $\mathrm{Cs}$ derivatives anti-

coagulant effect, could be yet founded and further studies are required.

\section{Acknowledgement}

The present work was funded by the Ministry of Higher Education and Scientific

Research, Tunisia.

\section{References}

1. H., Mittal, S.S., Ray, B.S., Kaith, J.K., Bhatia, Sukriti, J., Sharma, S.M., Alhassan, (2018). Recent progress in the structural modification of chitosan for applications in diversified biomedical fields. European Polymer Journal, 109, 402-434.

2. Z., Dong, H., Cui, Y., Wang, C., Wang, Y., Li, C., Wang, (2020). Biocompatible AIE material from natural resources: Chitosan and its multifunctional applications. Carbohydrate Polymers, 227, 115338.

3. L., Zhai, Z., Bai, Y., Zhu, B., Wang, W., Luo, (2018). Fabrication of chitosan microspheres for efficient adsorption of methyl orange. Chinese Journal of Chemical Engineering, 26, 657-666.

4. F., Ahmed, F.M., Soliman, M.A., Adly, H.A.M., Soliman, M., El-Matbouli, M., Saleh, (2019). Recent progress in biomedical applications of chitosan and its nanocomposites in aquaculture: A review. Research in Veterinary Science, 126, 68-82.

5. P.S., Bakshi, D., Selvakumar, K., Kadirvelu, N.S., Kumar, (2019). Chitosan as an environment friendly biomaterial - a review on recent modifications and applications. International Journal of Biological Macromolecules, In Press, Corrected Proof.

6. M.A., Gámiz-González, D.M., Correia, S., Lanceros-Mendez, V., Sencadas, J.L., Gómez Ribelles, A., Vidaurre, (2017). Kinetic study of thermal degradation of chitosan as a function of deacetylation degree. Carbohydrate Polymers, 167, 52-58.

7. C.T., Tsao, C.H., Chang, Y.Y., Lin, M.F., Wu, J.L., Han, K.H., Hsieh, (2011). Kinetic study of acid depolymerization of chitosan and effects of low molecular weight chitosan on erythrocyte rouleaux formation. Carbohydrate Research, 346, 94-102.

8. $\mathrm{S}$., $\mathrm{Wu},(2011)$. Preparation of water-soluble chitosan by hydrolysis with commercial $\alpha$ amylase containing chitosanase activity. Food Chemistry, 128, 769-772. 
9. H., Liu, J., Bao, Y., Du, X., Zhou, J.F., Kennedy, (2006). Effect of ultrasonic treatment on the biochemphysical properties of chitosan. Carbohydrate Polymers, 64, 553-559.

10. Z., Xia, S., Wu, J., Chen, (2013). Preparation of water-soluble chitosan by hydrolysis using hydrogen peroxide. International Journal of Biological Macromolecules, 59, 242-245.

11. Y.J., Jeon, S.K., Kim, (2000). Continuous production of chitooligosaccharides using a dual reactor system. Process Biochemistry, 35, 623-632.

12. S., Affes, I., Aranaz, M., Hamdi, N., Acosta, O., Ghorbel-Bellaaj, A., Heras, M., Nasri, H., Maâlej, (2019). Preparation of a crude chitosanase from blue crab viscera as well as its application in the production of biologically active chito-oligosaccharides from shrimp shells chitosan. International Journal of Biological Macromolecules, 139, 558-569.

13. S.B., Lin, Y.C., Lin, H.H., Chen, (2009). Low molecular weight chitosan prepared with the aid of cellulase, lysozyme and chitinase: Characterisation and antibacterial activity. Food Chemistry, 116, 47-53.

14. M., Gatto, D., Ochi, C.M.P., Yoshida, C.F., da Silva, (2019). Study of chitosan with different degrees of acetylation as cardboard paper coating. Carbohydrate Polymers, 210, 56-63.

15. F., Khan, D.T. N., Pham, S. F., Oloketuyi, P., Manivasagan, J., Oh, Y.M., Kim, (2020). Chitosan and their derivatives: Antibiofilm drugs against pathogenic bacteria. Colloids and Surfaces B: Biointerfaces, 185, 110627.

16. M., Hamdi, S., Hajji, S., Affes, W., Taktak, H., Maâlej, M., Nasri, R., Nasri, (2018). Development of a controlled bioconversion process for the recovery of chitosan from blue crab (Portunus segnis) exoskeleton. Food Hydrocolloids, 77, 534-548.

17. M., Hamdi, R., Nasri, S., Li, M., Nasri, (2019b). Bioinspired pH-sensitive Riboflavin controlled-release alkaline hydrogels based on blue crab chitosan: Study of the effect of wall polymer characteristics. International Journal of Biological Macromolecules, In Press, Journal Pre-proof.

18. S.H., Chang, H.T.V., Lin, G.J., Wu, G.J., Tsai, (2015). pH effects on solubility, zeta potential, and correlation between antibacterial activity and molecular weight of chitosan. Carbohydrate Polymers, 134, 74-81.

19. R.Q., Qian, R.W., Glanville, (2005). Methods for Purifying Chitosan. US Patent 2005, 6896809.

20. M.H., Ottey, K.M., Virum, O., Smidsred, (1996). Compositional heterogeneity of heterogeneously deacetylated chitosans. Carbohydrate Polymers, 29, 17-24. 
21. J., Brugnerotto, J., Desbrieres, G., Roberts, M., Rinaudo, (2001). Characterization of chitosan by steric exclusion chromatography. Polymer, 42, 9921-9927.

22. S., Liu, J., Sun, L., Yu, C., Zhang, J., Bi, F., Zhu, M., Qu, C., Jiang, Q., Yang, (2012). Extraction and characterization of chitin from the beetle Holotrichia parallela Motschulsky. Molecules, 17, 4604-4611.

23. G.A., O’Toole, (2011). Microtiter dish biofilm formation assay. Journal of Visualized Experiments, 47, 10-11.

24. R.D., Langdell, R.H., Wagner, K.M., Brinkhous, (1953). Effect of antihemophilic factor on one-stage clotting tests. Journal of Laboratory and Clinical Medicine, 41, 637-647.

25. R., Nasri, I., Ben Amor, A., Bougatef, N., Nedjar-Arroume, P., Dhulster, J., Gargouri, M., Karra Châabouni, M., Nasri, (2012). Anticoagulant activities of goby muscle protein hydrolysates. Food Chemistry, 133, 835-841.

26. E., Galli, A., Lakhdar, (2009). Extraction et caractérisation de la chitine et du chitosane obtenus à partir de biomasses. In : Chitine et Chitosane, du biopolymère à l'application, Crini, G., Badot, P.M., Guibal, E. (Eds.). Presses universitaires de Franche-Comté, 55-66.

27. M., Rinaudo, (2006). Chitin and chitosan: properties and applications. Progress in Polymer Science, 31, 603-632.

28. M., Hamdi, R., Nasri, S., Hajji, M., Nigen, S., Li, M., Nasri, (2019a). Acetylation degree, a key parameter modulating chitosan rheological, thermal and film-forming properties. Food Hydrocolloids, 87, 48-60.

29. L., Sun, J., Li, J., Cai, L., Zhong, G., Ren, Q., Ma, (2017). One pot synthesis of gold nanoparticles using chitosan with varying degree of deacetylation and molecular weight. Carbohydrate Polymers, 178, 105-114.

30. M., Jovanovic, J., Radivojevic, K., O'Connor, S., Blagojevic, B., Begovic, V., Lukic, J., Nikodinovic-Runic, V., Savic, (2019). Rhamnolipid inspired lipopeptides effective in preventing adhesion and biofilm formation of Candida albicans. Bioorganic Chemistry, 87, 209-217.

31. V., Carniello, B.W., Peterson, H.C., van der Mei, H.J., Busscher, (2018). Physicochemistry from initial bacterial adhesion to surface-programmed biofilm growth. Advances in Colloid and Interface Science, 261, 1-14.

32. N., Jemil, H., Ben Ayed, A., Manresa, M., Nasri, N., Hmidet, (2017). Antioxidant properties, antimicrobial and anti-adhesive activities of DCS1 lipopeptides from Bacillus methylotrophicus DCS1. BMC Microbiology, 17, 144-155. 
33. J., Coronel-Leon, A.M., Marques, J., Bastida, A., Manresa, (2015). Optimizing the production of the bio-surfactant lichenysin and its application in biofilm control. Journal of Applied Microbiology, 120, 99-111.

34. I., Younes, S., Sellimi, M., Rinaudo, K., Jellouli, M., Nasri, (2014). Influence of acetylation degree and molecular weight of homogeneous chitosans on antibacterial and antifungal activities. International Journal of Food Microbiology, 185, 57-63.

35. Y., Liu, Y., Jiang, J., Zhu, J., Huang, H., Zhang, (2019). Inhibition of bacterial adhesion and biofilm formation of sulfonated chitosan against Pseudomonas aeruginosa. Carbohydrate Polymers, 206, 412-419.

36. Z., Zhou, T., Chen, N., Mei, B., Li, Z., Xu, L., Wang, X., Wang, S., Tang, (2019), LED 209 conjugated chitosan as a selective antimicrobial and potential anti-adhesion material. Carbohydrate Polymers, 206, 653-663.

37. R., Campana, L., Casettari, E., Ciandrini, L., Illum, W., Baffone, (2017). Chitosans inhibit the growth and the adhesion of Klebsiella pneumoniae and Escherichia coli clinical isolates on urinary catheters. International Journal of Antimicrobial Agents, 50, 135-141.

38. L., McLandsborough, A., Rodriguez, D., Pérez-Conesa, J., Weiss, (2006). Biofilms: At the interface between biophysics and microbiology. Food Biophysics, 1, 94-114.

39. M., Croce, S., Conti, C., Maake, G.R., Patzke, (2016). Synthesis and screening of Nacyl thiolated chitosans for antibacterial applications. Carbohydrate Polymers, 151, 1184-1192.

40. L., Lin, L., Zhao, N., Gao, R., Yin, S., Li, H., Sun, L., Zhou, G., Zhao, S.W., Purcell, J., Zhao, (2019). From multi-target anticoagulants to DOACs, and intrinsic coagulation factor inhibitors. Blood Reviews, In Press, Corrected Proof.

41. M., Imran, M., Sajwan, B., Alsuwayt, M., Asif, (2019). Synthesis, characterization and anticoagulant activity of chitosan derivatives. Saudi Pharmaceutical Journal, In Press, Corrected Proof.

42. V., Margelidon-Cozzolino, X., Delavenne, J., Catella-Chatron, E., de Magalhaes, S., Bezzeghoud, M., Humbert, D., Montani, L., Bertoletti, (2019). Indications and potential pitfalls of anticoagulants in pulmonary hypertension: Would DOACs become a better option than VKAs? Blood Reviews, 37, 100579.

43. M., Nasri, (2017). Protein hydrolysates and biopeptides: Production, biological activities, and applications in foods and health benefits. A review. In: Toldra, F. (Ed.), Advances in Food and Nutrition Research, Vol. 81, Burlington: Academic Press, pp. 109-159. 
44. K., Heise, M., Hobisch, L., Sacarescu, U., Maver, J., Hobisch, T., Reichelt, M., Sega, S., Fischer, S., Spirk, (2018). Low-molecular-weight sulfonated chitosan as template for anticoagulant nanoparticles. International Journal of Nanomedicine, 13, 4881-4894.

45. J., Yang, K., Luo, D., Li, S., Yu, J., Cai, L., Chen, Y., Du, (2013). Preparation, characterization and in vitro anticoagulant activity of highly sulfated chitosan. International Journal of Biological Macromolecules, 52, 25-31.

46. B., Arasukumar, G., Prabakarana, B., Gunalan, M., Moovendhan, (2019). Chemical composition, structural features, surface morphology and bioactivities of chitosan derivatives from lobster (Thenus unimaculatus) shells. International Journal of Biological Macromolecules, 135, 1237-1245.

47. N.N., Drozd, Y.S., Logvinova, B.T., Shagdarova, A.V., Il'ina, V.P., Varlamov, (2019). Analysis of the action of quaternized chitosans with different molecular weight on anticoagulant activity of heparins in vitro. Bulletin of experimental biology and medicine, 167, 279-283.

48. W., Song, Q., Zeng, X., Yin, L., Zhu, T., Gong, C., Pan, (2018), Preparation and anticoagulant properties of heparin-like electrospun membranes from carboxymethyl chitosan and bacterial cellulose sulfate. International Journal of Biological Macromolecules, 120, 1396-1405.

49. J., Suwan, Z., Zhang, B., Li, P., Vongchan, P., Meepowpan, F., Zhang, S.A., Mousa, S., Mousa, B., Premanode, P., Kongtawelert, R.J., Linhardt, (2009), Sulfonation of papaintreated chitosan and its mechanism for anticoagulant activity. Carbohydrate Research, 344, 1190-1196. 
Table 1: Acetylation degrees and molecular weight of prepared blue crab chitosan and

derivatives.

\begin{tabular}{ccccccc}
\hline $\begin{array}{c}\text { Cellulase } \\
\text { hydrolysis (h) }\end{array}$ & ADI $(\%)$ & $\begin{array}{c}\text { Mw } \\
\left(\mathbf{g ~ m o l}^{-1}\right)\end{array}$ & AD (\%) & $\begin{array}{c}\text { Mw } \\
\left(\mathbf{g ~ m o l}^{-1}\right)\end{array}$ & AD (\%) & $\begin{array}{c}\text { Mw } \\
\left(\mathbf{g ~ m o l}^{-1}\right)\end{array}$ \\
\hline $\mathbf{0}$ & 17 & 125600 & 13 & 118900 & 8 & 115000 \\
$\mathbf{1}$ & $\mathrm{Nd}$ & 17800 & $\mathrm{Nd}$ & 59270 & $\mathrm{Nd}$ & 78430 \\
$\mathbf{3}$ & 17 & 10440 & 14 & 18540 & 9 & 16040 \\
\hline
\end{tabular}

Nd: not determined.

Acetylation degree was determined based on the ${ }^{13} \mathrm{C}$ NMR spectra.

Average molecular weight was determined based on the SEC chromatograms. 
Table 2: Blue crab chitosan derivatives thermal stability/degradation behavior as function of

\begin{tabular}{|c|c|c|c|c|c|c|c|c|c|}
\hline \multirow{2}{*}{ Parameters } & \multicolumn{3}{|c|}{ AD of $17 \%$} & \multicolumn{3}{|c|}{ AD of $13 \%$} & \multicolumn{3}{|c|}{ AD of $8 \%$} \\
\hline & UN_CsI & CsI-1 & CsI-3 & UN_CsII & CsII-1 & CsII-3 & UN_CsIII & CsIII-1 & CsIII-3 \\
\hline$\Delta \mathrm{W}(\%)$ & 8 & 8 & 8 & 7 & 8 & 8 & 6 & 7 & 7 \\
\hline $\operatorname{Td}\left({ }^{\circ} \mathbf{C}\right)$ & 53 & 49 & 41 & 55 & 52 & 48 & 58 & 53 & 51 \\
\hline $\operatorname{Tmax}\left({ }^{\circ} \mathbf{C}\right)$ & 203 & 111 & 99 & 218 & 127 & 99 & 224 & 143 & 123 \\
\hline Tf $\left({ }^{\circ} \mathbf{C}\right)$ & 253 & 174 & 142 & 260 & 180 & 170 & 267 & 215 & 192 \\
\hline$\Delta W(\%)$ & 58 & 62 & 64 & 57 & 61 & 63 & 56 & 60 & 62 \\
\hline $\operatorname{Td}\left({ }^{\circ} \mathbf{C}\right)$ & 276 & 240 & 207 & 281 & 256 & 222 & 289 & 259 & 238 \\
\hline $\operatorname{Tmax}\left({ }^{\circ} \mathbf{C}\right)$ & 460 & 306 & 295 & 466 & 319 & 304 & 474 & 402 & 355 \\
\hline $\mathbf{T f}\left({ }^{\circ} \mathbf{C}\right)$ & 495 & 427 & 395 & 496 & 442 & 409 & 497 & 454 & 446 \\
\hline
\end{tabular}

\begin{tabular}{crrrrrrrrr} 
Residue (R; \%) & 34 & 30 & 28 & 36 & 31 & 29 & 38 & 33 & 31 \\
$\operatorname{Tg}\left({ }^{\circ} \mathbf{C}\right)$ & 188 & 166 & 142 & 191 & 172 & 157 & 202 & 188 & 173 \\
\hline
\end{tabular}

Cs: chitosan; UN_Cs: undigested chitosan; Cs-1: Cs treated with Cellulase for 1 h; Cs-3: Cs treated with Cellulase for $3 \mathrm{~h} ; \boldsymbol{\Delta} \mathbf{w}$ : weight loss (\%); Td: initial degradation temperature; Tmax: maximal degradation temperature; Tf: final degradation temperature; Tg: glass transition temperature. 
Table 3: Blue crab chitosan derivatives anti-coagulant activity as function of their $\mathrm{AD}$ and $\mathrm{Mw}$, based on the activated partial thromboplastin time (APTT), Quick time (QT) and Thrombin time (TT). Values (seconds) presented are the mean of triplicate analyses.

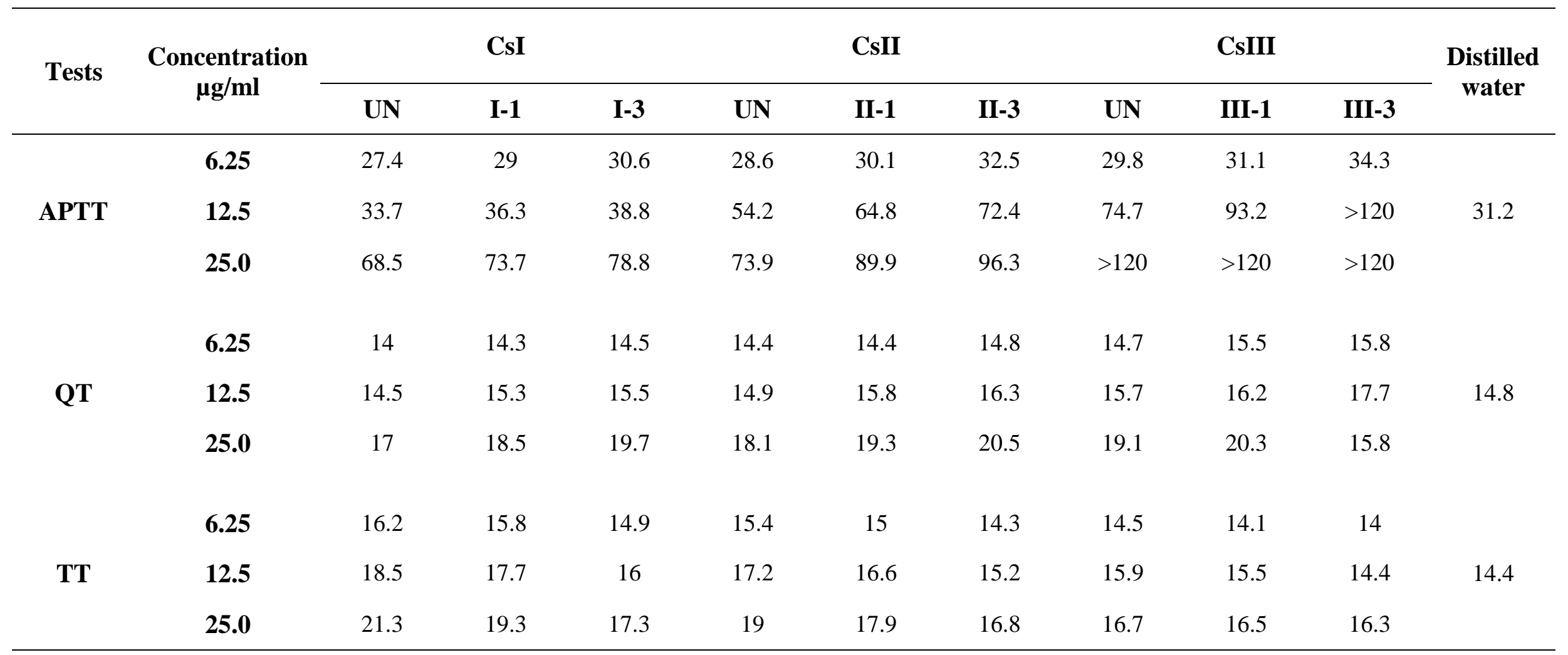

Cs: chitosan; UN: undigested chitosan; Cs-1: Cs treated with Cellulase for $1 \mathrm{~h}$; Cs-3: Cs treated with Cellulase for 3 h. 


\section{Figures captions}

Figure 1: ${ }^{13} \mathrm{C}$ NMR spectra of Cs derivatives: Cs with AD of $17 \%$ (A), Cs with AD of $13 \%$ (B) and Cs with AD of $8 \%$ (C). Cs: chitosan; UN_Cs: undigested chitosan; Cs-3: Cs treated with Cellulase for $3 \mathrm{~h}$.

Figure 2: XRD spectra of Cs and Cs derivatives: Cs with AD of 17\% (A), Cs with AD of 13\% (B) and Cs with AD of 8\% (C). Cs: chitosan; UN_Cs: undigested chitosan; Cs-1: Cs treated with Cellulase for $1 \mathrm{~h}$; Cs-3: Cs treated with Cellulase for $3 \mathrm{~h}$.

Figure 3: TGA (A) and DTG (B) thermograms of Cs and Cs derivatives. Cs: chitosan; UN_Cs: undigested chitosan; Cs-1: Cs treated with Cellulase for 1 h; Cs-3: Cs treated with Cellulase for $3 \mathrm{~h}$.

Figure 4: Microbial adhesion inhibition (A) and pre-formed biofilm disruption effect (B) of Cs and Cs derivatives. Cs: chitosan; UN_Cs: undigested chitosan; CsI: Cs with AD of 17\%; CsII: Cs with AD of 13\%; CsIII: Cs with AD of 8\%; Cs-1: Cs treated with Cellulase for $1 \mathrm{~h}$; Cs-3: Cs treated with Cellulase for $3 \mathrm{~h}$. 
Fig. 1

(A)
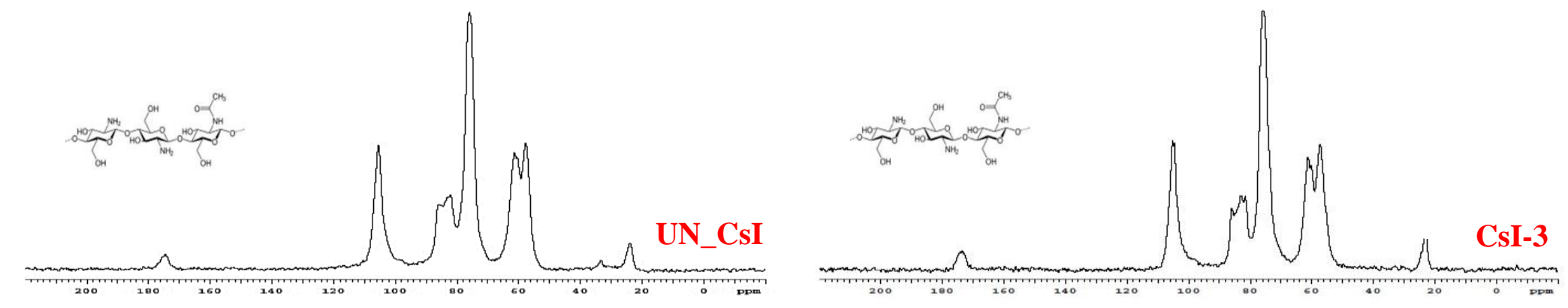

(B)
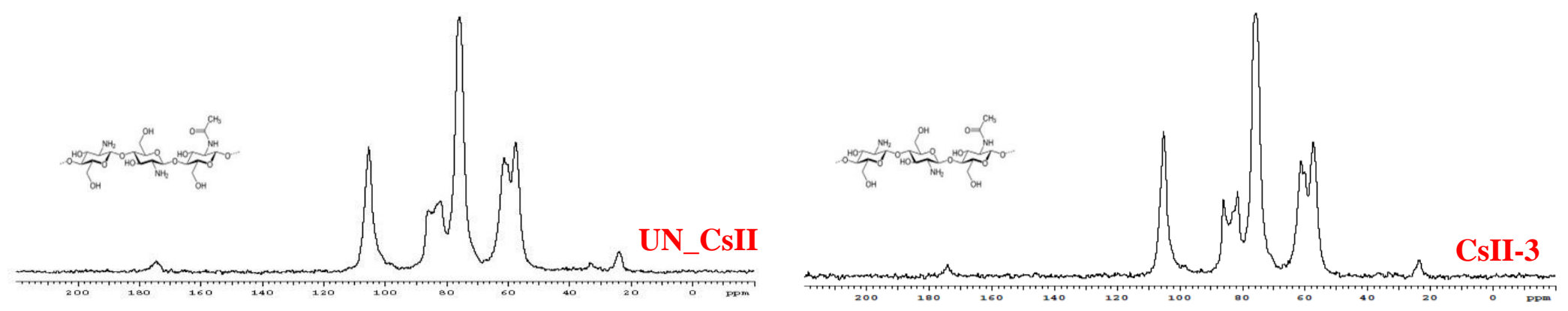

(C)
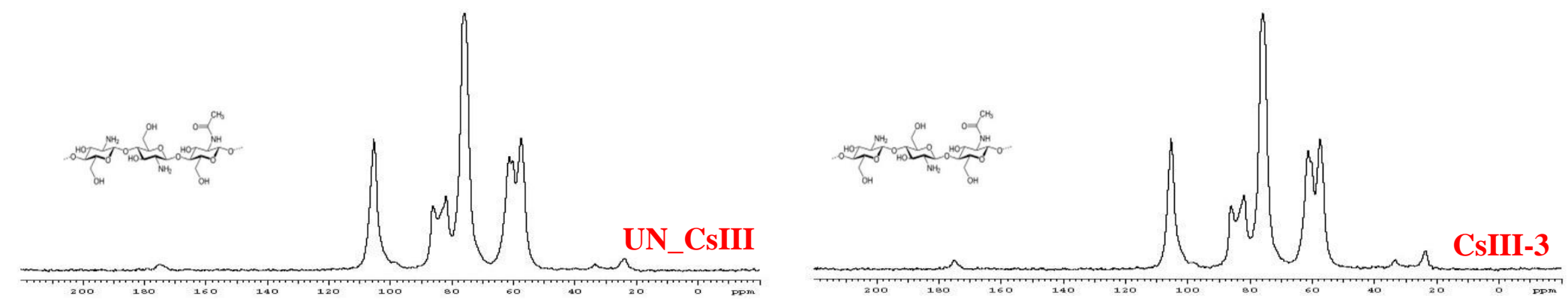
Fig. 2
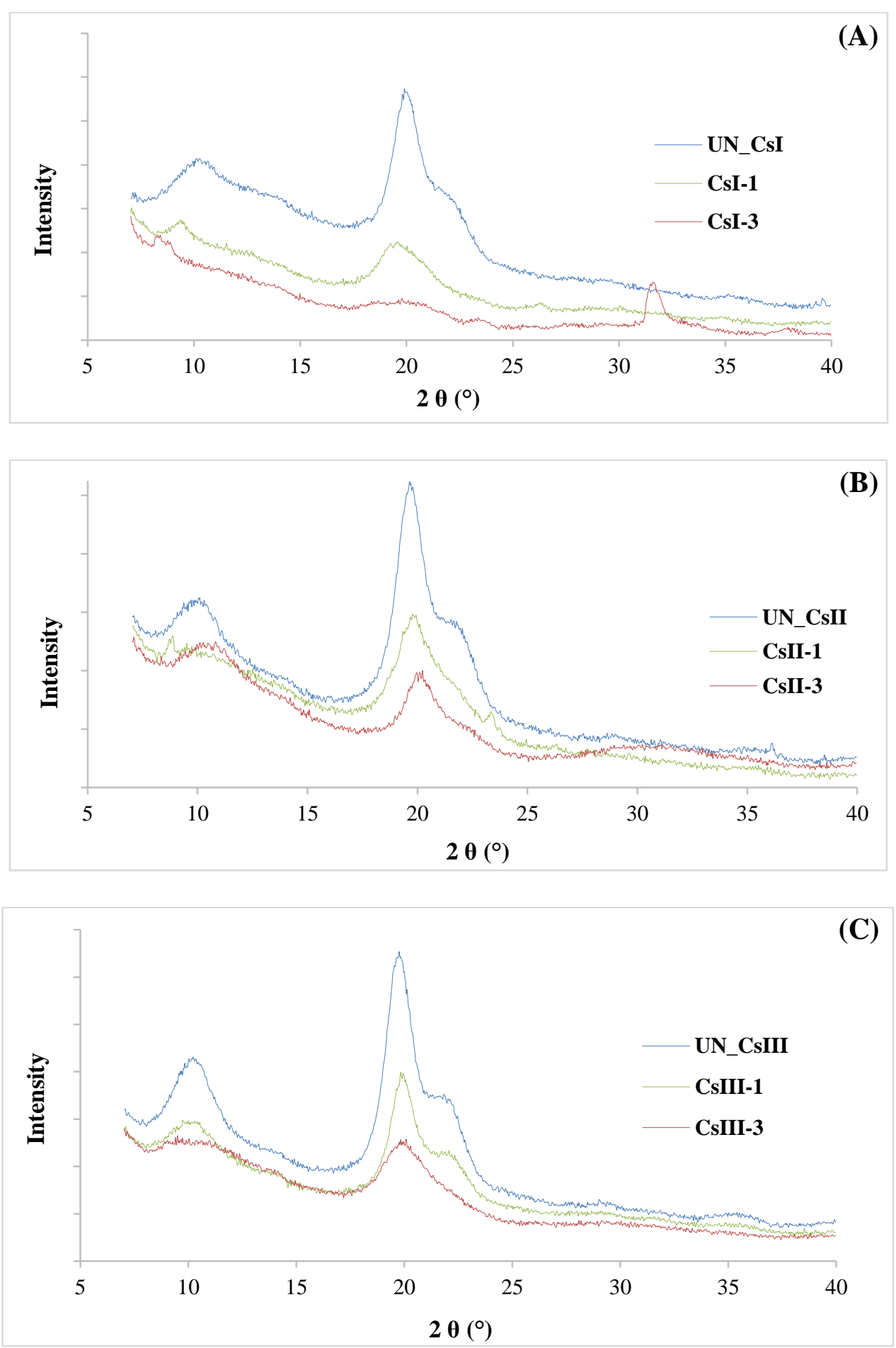
Fig. 3

(A)
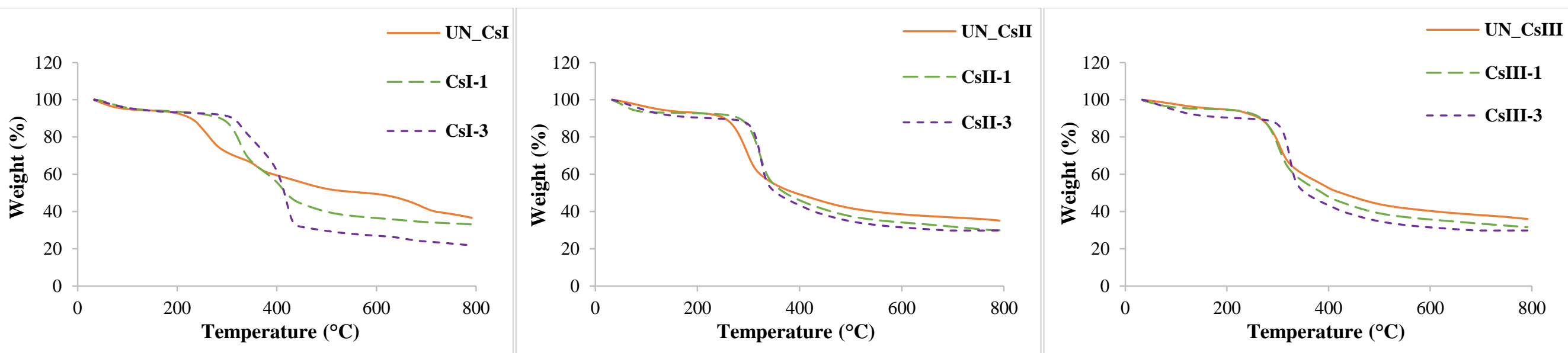

(B)
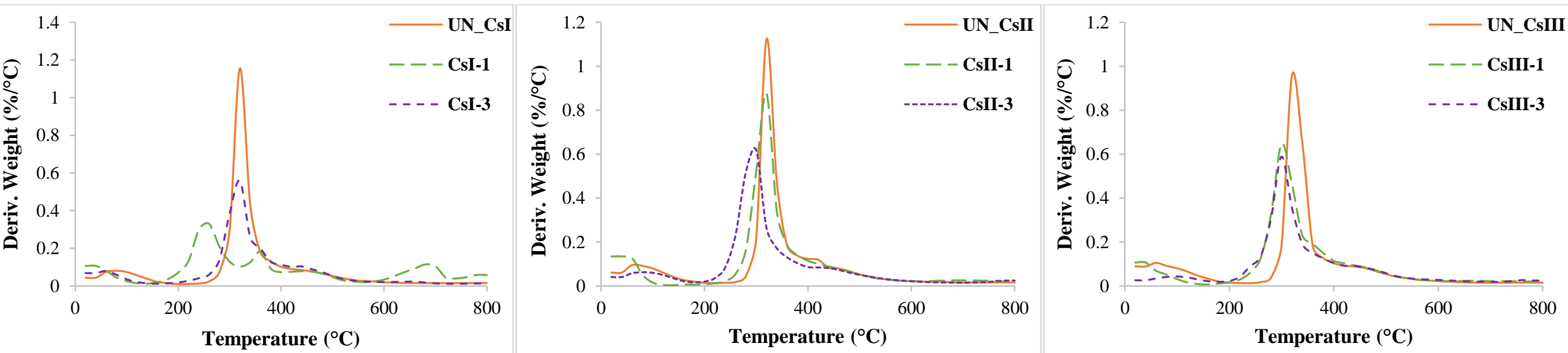
Fig. 4
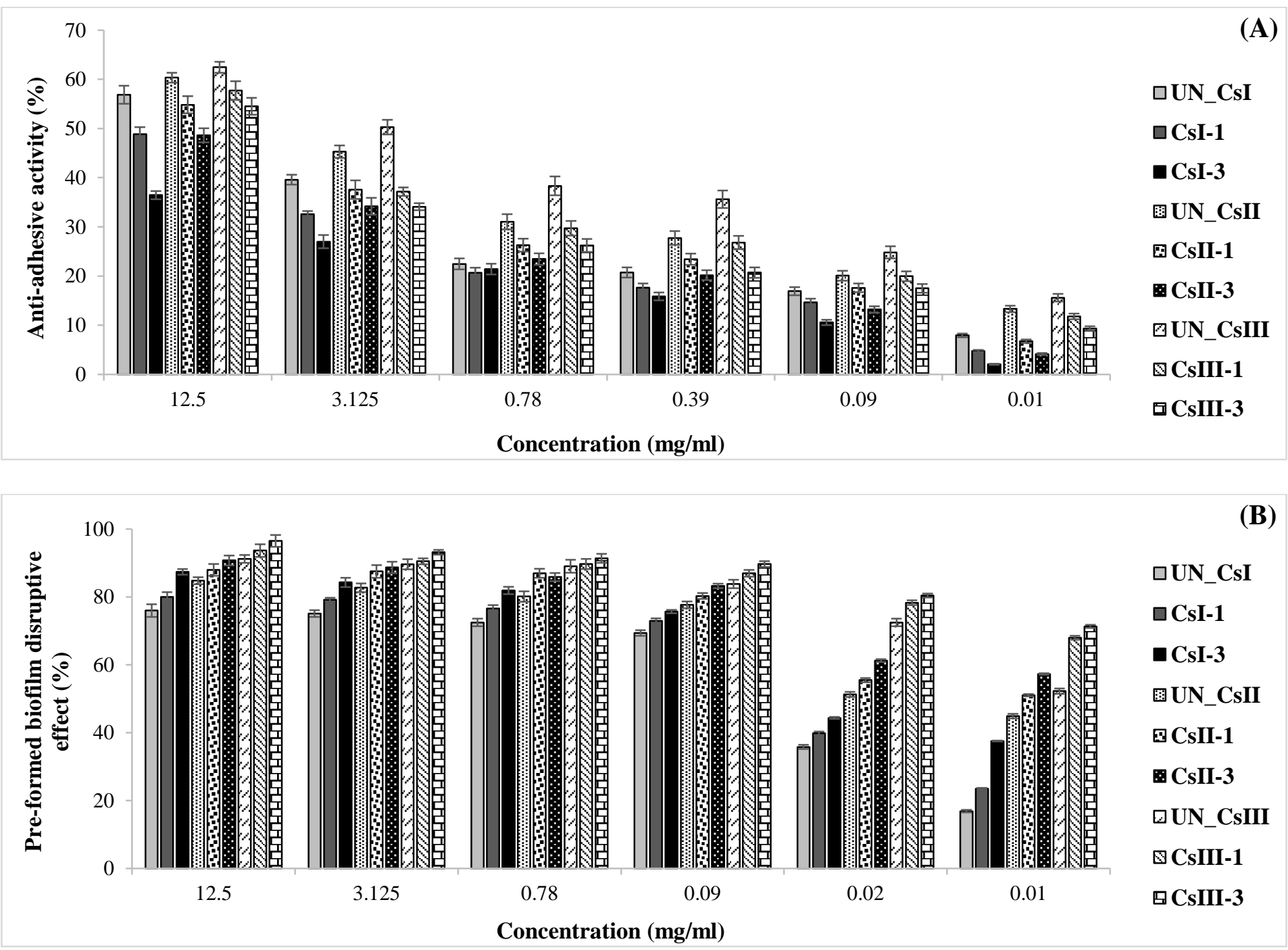
Sfax, $24^{\text {th }}$ of April 2020

\section{Credit author statement}

Marwa HAMDI: Conceptualization, Methodology, Validation, Formal analysis, Investigation, Writing-Editing, Visualization.

Rim NASRI: Resources, Supervision.

Ikram BEN AMOR: Investigation.

Suming LI: Resources, Supervision.

Jalel GARGOURI: Investigation.

Moncef NASRI: Resources, Supervision, Review.

\section{Dr. Marwa HAMDI}

Laboratory of Enzymatic Engineering and Microbiology, National School of Engineers of Sfax, Sfax. B.P.1173, 3038 Sfax, Tunisia.

E-mail: marwahamdi50@yahoo.fr 